\title{
Diversity of Research Participants Benefits ESL/EFL Learners: Examining Student-Lecturer Disagreements in Classrooms
}

\author{
Pattrawut Charoenroop ${ }^{1}$ \\ ${ }^{1}$ English as an International Language Program, Chulalongkorn University, Bangkok, Thailand \\ Correspondence: Pattrawut Charoenroop, English as an International Language, Chulalongkorn University, \\ Phyathai Road, Pathumwan, Bangkok, Thailand. Tel: 66-8-1003-0840. E-mail: pattrawut.ch@gmail.com
}

Received: January 18, 2016 Accepted: March 20, 2016 Online Published: March 22, 2016

doi: 10.5539/elt.v9n4p214 URL: http://dx.doi.org/10.5539/elt.v9n4p214

\begin{abstract}
Reviews of literature made manifest that native English speakers who were research participants in many studies on disagreements were Americans (e.g., Beebe \& Takahashi, 1989; Takahashi \& Beebe, 1993; Dogacay-Aktuna \& Kamisli 1996; Rees-Miller, 2000; Guodong \& Jing, 2005; Chen, 2006). The excessive use of Americans as research participants presented a rather restricted view on how the disagreements could be performed by native speakers of English. These studies exhibited that Americans in a classroom context normally began their student-lecturer disagreements with a positive comment (e.g., 'The idea is interesting but...'). Based on these results, the ESL/EFL learners might over-generalize from Americans to other groups of native English speakers and consequently postulate that all native English speakers initiate their student-lecturer disagreements with an optimistic remark. This current study chose a group of 13 Canadians and investigated their disagreement strategies in the identical context. The data were collected by videotaping the participants' classroom for three hours every week for five consecutive weeks. Results showed that the participants normally disagreed with their lecturer explicitly but mitigated their explicit disagreements with some justification (e.g., 'No because...'). The findings underscored that Americans and Canadians did not normally use the same disagreement strategies in the classroom context. If future studies increasingly use British English, Australians, New Zealanders or South Africans as research participants and investigate their expressions of student-lecturer disagreement, the ESL/EFL learners will become keenly aware of differences across all native English speakers. In other words, they will be able to avoid over-generalizing from Americans to other native English speakers.
\end{abstract}

Keywords: disagreement strategies, strong and weak disagreements, native speakers of English, politeness theory

\section{Introduction}

Henrich et al. (2010, p. 61) proposed an acronym 'WEIRD' to represent Western, Educated, Industrialized, Rich, and Democratic people. In the realm of behavioral science research, the participants most frequently used to represent 'WEIRD' were empirically attested to be young, educated and middle-class Americans. Henrich et al. (2010) contended that the excessive use of these Americans as research participants might be conducive to population invariability. The ESL/EFL learners, for example, could misperceive the results from the narrowly defined samples. The same holds true in many studies on disagreement. There are an abundant number of studies (e.g., Beebe \& Takahashi, 1989a, 1989b; Rees-Miller, 2000; Locher, 2004; Guodong \& Jing, 2005; Chen, 2006) that used Americans as research participants. Regardless of how the data were collected-either implicitly or explicitly elicited, these studies yielded consistent results exemplifying that Americans did not directly disagree with the lecturer but typically commenced their expressions of disagreement with a positive statement, as shown in (1).

(1) While that is true, no doubt,...

Rees-Miller (2000, p. 1108)

The extract (1) illustrates that Americans do not immediately express their disagreement but initially reiterate what was said by the lecturer in an optimistic way. To some extent, the positive statement implies that the speaker agrees with the lecturer. However, the speaker eventually reveals that $\mathrm{s} /$ he does not entirely agree with the lecturer's opinion. In some cases, the expressions of disagreement are postponed by a discourse connective 'but' (Locher, 2004, pp. 135-137) as in 'yes, but...', a conventional expression for disagreement (cf. Bjorge, 2012). Beginning the expressions of disagreement with a positive comment or a token of agreement, the speaker 
can firstly acknowledge the lecturer's need for solidarity. As a result, the threat of disagreement that follows can be counteracted and the lecturer's positive face can be saved. In addition, Rees-Miller (2000, pp. 1106-1107) disclosed that American professors regularly commenced their lecturer-student disagreements with a positive remark, as shown in (2). Although the extract (2) may not be the focus of this current study, it is to show that Americans regardless of their power status in the classroom often made a pleasant comment to strengthen solidarity before performing the positive-face threatening act of disagreement.

(2) The kind of explanation you're giving is useful in some ways, but ...

Rees-Miller (2000, p. 1107)

The instantiation of these two extracts displays how Americans usually express their disagreements in the classroom context. The results from the past studies (that overly relied on Americans) might inculcate the ESL/EFL learners to expect that all native English speakers (Note 1) would abide by the same norm. This argument can turn out to be sensible because all native English speakers' cultural backgrounds are purported to be compatible (e.g., Hall, 1976; Hofstede, 1980; Markus \& Kitayama, 1991; Oyserman et al., 2002; Morling \& Lamoreaux, 2008). Henrich et al. (2010, pp. 79-81), however, did not agree with the preceding assumption and pointed out that American participants cannot virtually represent all native English speakers. For instance, they are more individualistic than other native English speakers. Thus, this current study used Canadians as research participants and examined their expressions of student-lecturer disagreements in the classroom context. Findings from this study can enrich the ESL/EFL learners' perception of other native English speakers, especially how they normally express their student-lecturer disagreements in the classroom context.

\section{Literature Review}

\subsection{Disagreement in the Cross-Cultural Framework}

Several dichotomous classifications have been used to stipulate cultural differences between Westerners and non-Westerners. They are individualism-collectivism, low- and high-context cultures and independent- and interdependent construal of self (e.g., Scollon \& Scollon, 1995; Hofstede, 2001; Gudykunst, 2003; Varner \& Beamer, 2005). These dichotomies have been purported to govern people's communication strategies. Gudykunst (2001, p. 37), for example, contended that Westerners, whose cultures are individualistic, low-context and independent, are more likely to express their opinions directly, precisely, clearly and absolutely. To the contrary, non-Westerners, whose cultures are collectivistic, high-context and interdependent, tend to express their opinions indirectly, ambiguously, implicitly and probabilistically.

In relation to this study, Westerners and non-Westerners can be broadly expected to perform their student-lecturer disagreements differently due to their divergent cultural backgrounds. Generally speaking, disagreement is a positive-face threatening act (Brown \& Levinson, 1987, pp. 68-74, pp. 102-117) that can be harmful to the hearer's need for harmony (e.g. Rees-Miller, 2000, p. 1089). Based on this traditional assumption, the speaker is encouraged to mitigate his/her disagreement particularly when the solidarity is a chief goal to be maintained in their social interaction. In the identical context, however, people with different cultural backgrounds may be expected to express this positive-face threatening act in various ways. Following Gudykunst (2001), Westerners' performances of disagreement are more likely to be unmitigated; while non-Westerners' disagreement should be seen mitigated. Kieu (2006), albeit over-generalized, confirmed that Westerners normally performed their disagreements explicitly and frankly, but non-Westerners usually expressed their disagreements implicitly and tacitly, that is, their disagreements required indirect delivery with softening modifications in order to increase in-group solidarity or minimize the imposition. If Kieu's (2006) conclusion is legitimate, the next question is whether a particular group of research participants adequately represent all Westerners and all non-Westerners.

\subsection{Americans as Research Participants}

In many studies on disagreements (e.g., Beebe \& Takahashi, 1989; Takahashi \& Beebe, 1993; Dogacay-Aktuna \& Kamisli 1996; Rees-Miller, 2000; Guodong \& Jing, 2005; Chen, 2006), Americans were frequently used as research participants to epitomize native English speakers. Most of the studies agreed that Americans usually commenced their disagreements with a positive comment, especially when disagreeing with a more powerful interlocutor. Beebe and Takahashi (1989) and Takahashi and Beebe (1993), for example, compared native speakers of Japanese and American speakers of English when they expressed disagreements in lower-to-higher-status situations. They similarly reported that Americans commonly began their performance of disagreement with a pleasant comment to satisfy the lecturer's needs for commonality before they disagreed. Takahashi and Beebe (1993) further corroborated that their American participants often used more polite strategies than their Japanese participants when disagreeing with a more powerful interlocutor. Dogacay-Aktuna and Kamisli (1996) studied how native speakers of Turkish and American speakers of English expressed their disagreement in workplace. They discovered that Americans were sensitive to the interlocutor's status and 
usually initiated their disagreements with a positive statement. In a similar vein, Rees-Miller (2000, p. 1097) examined Americans when disagreeing with their professors in an academic setting and noticed that her participants frequently encoded a partial agreement to initiate their expressions of disagreement. By doing this, the participants were able to counteract the threat that was harmful to the lecturer's positive face.

The researchers of most studies above simply generalized the results based on their American participants to all native English speakers (e.g., Beebe \& Takahashi, 1989; Takahashi \& Beebe, 1993; Dogacay-Aktuna \& Kamisli 1996). They took it for granted that their American participants' norm comported with all native English speakers' norms. This evasiveness would certainly have some potential to mislead the ESL/EFL learners to construe that there is no difference (at all) across all populations of native English speakers, especially when they deal with student-lecturer disagreements.

\subsection{Disagreement Strategies}

Disagreement is an expression of an opinion that is incompatible with the preceding opinion expressed by the hearer (in a dyadic talk). Disagreement is often perceived as an inherently face-threatening act that easily jeopardizes the hearer's face (cf. Brown \& Levinson, 1987, p. 66). Therefore, disagreements in many institutional contexts are encouraged to be mitigated. As a result, the mitigated disagreements will not be threatening to the hearer's face. The view above was used as a point of departure to distinguish two sets of disagreement strategies. They are (i) strong disagreements, i.e. disagreements that are not mitigated and (ii) weak disagreements, i.e. disagreements that are mitigated. All strategies are shown in Table 1.

Table 1. Disagreement strategies

\begin{tabular}{|c|c|c|}
\hline Sets of strategies & $\begin{array}{l}\text { Disagreement } \\
\text { strategies }\end{array}$ & Realizations \\
\hline \multirow{5}{*}{$\begin{array}{l}\text { Strong } \\
\text { disagreements }\end{array}$} & \multirow{3}{*}{$\begin{array}{l}\text { Explicit } \\
\text { disagreements }\end{array}$} & 'no' (Locher, 2004, pp. 143-145) \\
\hline & & 'I disagree.' (Emmerson, 2004, p. 64) \\
\hline & & 'I don't agree.' (Brieger \& Sweeney, 2000, p. 188) \\
\hline & \multirow{2}{*}{$\begin{array}{l}\text { Unmitigated } \\
\text { disagreement }\end{array}$} & 'We can't do that.' (Emmerson, 2004, p. 64) \\
\hline & & 'That's not practical.' (Walkinshaw, 2007, p. 280). \\
\hline \multirow{13}{*}{$\begin{array}{l}\text { Weak } \\
\text { disagreements }\end{array}$} & \multirow{7}{*}{$\begin{array}{l}\text { Delayed } \\
\text { disagreements }\end{array}$} & 'Well, but it is not.' (Locher, 2004, p. 118) \\
\hline & & 'Oh! it doesn't look red to me.' (Charoenroop, 2014, p. 149) \\
\hline & & 'To be honest,...' (Emmerson, 2004, p. 65) \\
\hline & & 'I think it's wrong,...' (Locher, 2004, p. 164) \\
\hline & & 'I'm afraid,...' (Sweeney, 2003, p. 151) \\
\hline & & 'You could be right, but...' (Brieger \& Sweeney, 2000. p. 178), \\
\hline & & 'I know what you mean, but...' (Emmerson, 2004, p. 65). \\
\hline & \multirow{4}{*}{$\begin{array}{l}\text { Internally } \\
\text { Mitigated } \\
\text { Disagreements }\end{array}$} & 'I don’t quite agree' (Jones \& Alexander, 2003, p. 113) \\
\hline & & 'It might mean something' (Locher, 2004, p. 129) \\
\hline & & 'I'm not sure we can do that.' (Emmerson, 2004, p. 64).' \\
\hline & & 'Won't some people find that a little early.' (Emmerson, 2004, p. 65)' \\
\hline & \multirow[t]{2}{*}{$\begin{array}{l}\text { Disagreements } \\
\text { with Justification }\end{array}$} & $\begin{array}{l}\text { 'I don't agree with that point because...' (Jones \& Alexander, 2003, p. } \\
\text { 113) }\end{array}$ \\
\hline & & 'That's going to happen anyway because...' (Locher, 2004, p. 251) \\
\hline
\end{tabular}

Disagreements that are not mitigated are categorized as 'strong disagreements.' There are two sub-strategies under the strong disagreements: (i) explicit disagreements, and (ii) unmitigated disagreements. The former encompasses disagreements that are explicitly performed, that is, the act of saying per se explicitly communicates the illocutionary act of disagreement. In other words, interpreting the explicit disagreements is likely to be context-independent. The latter refers to disagreements that are expressed without any softening 
devices. The interpretation of unmitigated disagreements is context-dependent, that is, a preceding utterance must be taken into account in order to conclude that a responsive utterance is illocutionarily disagreement. On the other hand, disagreements that are mitigated are labeled as 'weak disagreements.' There are three sub-strategies under the weak disagreements: (i) delayed disagreements, (ii) internally mitigated disagreements, and (iii) disagreements with justification. Firstly, disagreements that are not spontaneously produced but prefaced with a token of agreement, a positive comment, or even a hesitation marker are subsumed as 'delayed disagreements.' Secondly, disagreements that are mitigated through some internal modifications such as the use of hedges, questions or indirectness are categorized as internally mitigated disagreements. Thirdly, some disagreements can be mitigated by an ensuing justification or clarification. The presence of justification or clarification ratifies the foregoing disagreements.

The taxonomy in Table 1 exemplifies how disagreement strategies are realized without any combination of other strategies. In fact, the combination of two or three disagreement strategies in spontaneous talks is permissible. Table 2 instantiates 6 possible realizations that display two- or three-strategies combinations.

Table 2. Combined disagreement strategies

\begin{tabular}{lll}
\hline Sets of strategies & Disagreement strategies & Realizations \\
\hline $\begin{array}{l}\text { Strong + } \\
\text { Weak disagreements }\end{array}$ & Explicit + Justification & 'no, because...' \\
& & 'The idea is not practical because...' \\
Weak + & Delayed + Internally Mitigated & 'I think it $m i g h t$ be wrong.' \\
Weak & Delayed + Justification & 'I think it's wrong because...' \\
Disagreements & Internally Mitigated + Justification & 'I don't quite agree because...' \\
& Delayed + Internally Mitigated + Justification & 'I think it might be wrong because...' \\
\hline
\end{tabular}

\section{Methodology}

\subsection{Populations and Samples}

The research participants were 13 Canadian speakers of English. There were 5 males (Noah, Felix, Matthew, Antoine and Ryan), and 8 females (Emma, Victoria, Olivia, Clara, Grace, Ava, Sophie and Alice)-these names were pseudonyms. Their age range was between 19-27 years old. All of them were university students from Canada majoring in Tourism and Management and participated in this sudy while temporarily staying in Thailand for 4 months. Felix, Victoria and Clara had been in Thailand on travelling purposes twice but only for a few weeks. The participants' self-report revealed that none of them had previously learned to speak Thai. They were monolingual who used English as their first language, except Noah, Olivia, Clara and Ava who were bilingual speaking Canadian-French and English.

Phil was the professor who taught the class throughout the semester. His name was also pseudonym. He was a 45-year-old, American-Thai lecturer who was bilingual. Phil had strong background in teaching at the tertiary level in Thailand. He always encouraged his students to participate in class discussions and provided an equal opportunity for everyone to speak. Phil addressed his students by their first names. Based on my observation, he was friendly; as a consequence, the participants felt comfortable talking to him. Detailed information about the class and the lecturer is re-presented in Table 3. 
Table 3. Samples' information and their classroom context

\begin{tabular}{ll}
\hline & Canadian Speakers of English \\
\hline Mamples & \\
Male: Female & $5: 8$ \\
Nationality: Native Language & Canadian: English \\
Age Range & $19-27$ (mean 21.92) \\
Level of Education & Second- and Third-year undergraduate \\
& \\
Classroom Context & \\
Subject & Cross-cultural communication \\
Class Period & 3 hours per week (9-12) \\
Duration of Classroom Videotaping & Jan 2013-Mar 2013 \\
Instructor (Gender, Age, Nationality) & Male, 45, American \\
Medium of Instruction & English \\
\hline
\end{tabular}

\subsection{Research Instrument}

The data was collected by means of classroom videotaping. Following Bardovi-Harlig (2013, p. 73), the participants' pragmatic knowledge should by no means be elicited explicitly when pragmatic knowledge is not explicitly taught to the participants. In other words, the participants were not explicitly taught how to disagree with the lecturer in English; therefore, their performance of disagreement should not be deliberately elicited. Collecting naturally-occurring data in a natural setting, where the students and the lecturer were unaware that their expressions of disagreement were captured for analysis, can be implicit. In addition, data obtained implicitly from classroom videotaping can be claimed to be spontaneous, reflecting what the speakers actually say rather than what they are planning to say. This type of data can be a source of rich pragmatic structures (e.g., Kasper \& Dahl, 1991; Cohen, 1996; Yuan, 2001).

\subsection{Data Collection}

Prior to the procedure of videotaping, an information sheet and a consent form were given to all participants, providing instructions of the research project. The participants reserved the right to accept or refuse the invitation to be involved in the project at any time. If this appears to be the case, his or her expression of disagreement will be abandoned (fortunately, none of them refused the invitation). There was no specification of any kind to notify the participants that their performance of disagreement was observed. All participants, however, were aware that their general classroom conduct was being captured. The videotape recorder was set up in front of the class 15 minutes prior to the beginning of each class. It mainly recorded the students' interactions with the lecturer.

The classroom was videotaped for 3 hours every week for 5 consecutive weeks. The researcher videotaped the participants since the first week after they had arrived in Thailand. This is to ensure that their pragmatic knowledge was not, or at least minimally, interfered with by the Thai pragmatic knowledge after they had immersed themselves in Thai culture.

\subsection{Data Analysis}

The data appearing on the first week of videotaping was removed from the analysis in order to increase the data reliability because the participants were allowed to be familiar with the data collection method at least for three hours. The naturally-occurring data after the first week was transcribed in a form of talk exchanges between a student and the lecturer. In each transcription, there was at least one student-lecturer disagreement embedded. The transcription conventions can be seen in Appendix A. All disagreements were counted to find out how many times the students disagreed with the lecturer in 4 weeks or 12 hours. The student-lecturer disagreements were carefully analyzed in terms of disagreement strategies based on the taxonomy in Tables 1 and 2. The highest frequency or the norm of disagreement strategies used by the participants was underscored. The frequency was converted to percentage. In these stages, a rater who had a research background in discourse analysis provided assistance in scrutinizing the accuracy of the transcripts as well as the analysis. 


\section{Results}

In 4 weeks or 12 hours, the participants produced 108 disagreements, which were extracted from 94 talk exchanges. The participants never used 'strong disagreements' as described in Table 1. They always mitigated their disagreements with either a positive comment or some justification. In other words, the participants used combined strategies whenever they disagreed with their lecturer explicitly. The use of the combined strategies suggested that the participants also wanted to decrease the threat of their explicit disagreements. In 108 tokens, the participants most often initiated their expressions of disagreement explicitly with a negative marker, which is typically 'no.' In the same turn, the participants continued to buttress their explicit disagreements with some justification or clarification (cf. strong + justification strategies in Table 2). This combined strategy was found to be their norm because it was used in 67 tokens or 62.03 percent. The use of other disagreement strategies is presented in Appendix B. In the following section, three extracts are purposefully selected to delineate how the norm was realized.

Extract 1 demonstrates how Ryan expressed his disagreement explicitly. In this extract, Ryan performed his disagreement one time in turn 3 but continued to give some justification to support his argument in turns 5 and 6 .

\section{Extract 1}

1) Prof. Phil: You will never call anyone as IT

2) Prof. Phil: (short pause) It's not polite

3) Ryan: (a student raises his index finger) № (short pause) unless we like them

4) Prof. Phil: Really(/)

5) Ryan: And some people call their child (short pause) IT=

6) Ryan: =BUT it doesn't have any mood in it

In this extract, Prof. Phil contended that his students did not address anyone by the third-person singular pronoun-'it.' He argued that the use of this pronoun as an address term implies impoliteness. In turn 3, Ryan raised his index finger asking for permission to get the floor and began to express his contrary opinion. His explicit disagreement was initiated by a negative marker 'no' disputing that the third-person singular pronoun could be used to address someone. Ryan further reasoned his argument that this address term could be used for someone we disliked. The use of the first-person plural pronoun in Ryan's explanation implies that his argument is also true for the professor. In the next turn, Prof. Phil uttered 'really' in a rising tone aiming to ask for a clarification. The professor expected Ryan to buttress his argument in more detail. However, Ryan did not further justify his argument but supported his explicit disagreement with another situation where the use of this pronoun was permissible and was not perceived impolite. Ryan corroborated that 'it' could sometimes be used to address a child and clarified that its utility in this particular context did not connote any negative consequences. In sum, this extract showed how an explicit disagreement was softened by two pieces of justification that followed.

Extract 2 illustrates how Emma disagreed with the lecturer. In this talk exchange, Emma expressed her disagreement twice in turn 4 and again between turns 6 and 8 .

\section{Extract 2}

1) Prof. Phil: Give me another word that ends with -ness

2) Alice: Sorrowfulness

3) Prof. Phil: Yeah yeah sorrowfulness

4) Emma: (the student shakes her head) No not a word

5) Prof. Phil: IT I:::S (short pause) sorrowfulness is an English word

6) Emma: (P) sorrowfulness(/) (P) (the student shakes her head) NO:.:

7) Emma: (short pause) Not in English

8) Emma: (short pause) Never heard of it

9) Prof. Phil: Really(/)

10) Emma: (short pause) I've heard only sorrow

11) Emma: It sounds really weird (P) sorrowfulness (P)

Prof. Phil asked the students to give him another English noun that ends with "-ness" as its suffix. Alice coined 
'sorrowfulness' to the class discussion. In turn 3, Prof. Phil agreed with Alice and confirmed that the lexical derivation conformed to the English morphological rule under discussion. In turn 4, Emma stepped in and disagreed with the lecturer. She began her expression of disagreement explicitly with a negative marker 'no.' Emma's linguistic realization was supported by headshaking to display disagreement non-verbally. Obviously, Emma's disagreement was not prefaced by any positive statements. By contrast, she explicitly contended that 'sorrowfulness' was a non-word. In turn 5, Prof. Phil ratified the existence of 'sorrowfulness' in the English glossary. Emma's second disagreement was expressed explicitly in the next turn. She reiterated the word softly in a rising tone to question the lecturer about his certainty. Then, she disputed that 'sorrowfulness' was not an English word. Emma accompanied her linguistic realization with another headshaking gesture. In turns 7 and 8 , Emma exhibited that 'sorrowfulness' was not an English word due to the fact that she had never heard it before. Prof. Phil did not explain the derivation of the word but urged Emma to think about it again. In turns 10 and 11, Emma insisted that she had heard 'sorrow' but had never heard 'sorrowfulness.' Based on her background knowledge, she clarified that 'sorrowfulness' sounded weird to her. In sum, this extract gives evidence that Emma did not preface her expression of disagreement with a positive statement. Her explicit expressions of disagreement, however, were modified by some justification.

Extract 3 shows how Clara expressed her explicit disagreement. In this extract, Clara performed her disagreement three times in turns 5, 7 and 9.

\section{Extract 3:}

1) Clara: How do I say (short pause) I don't want my food TOO spicy

2) Clara: (short pause) I want OK spicy

3) Clara: (long pause) That that's what I want to say

4) Prof. Phil: /maî $\mathrm{p}^{\mathrm{h}}$ З่d mâ:k/=

5) Clara: $=$ NO I WANT spicy=

6) Prof. Phil: =Yea::h BUT you want NOT TOO spicy

7) Clara: NO::: I want how they make it FOR (short pause) [YOU( $($ )

8) 8. Prof. Phil: / /maî $\mathrm{p}^{\mathrm{h}}$ 3̀ mâ:k/]

9) Clara: (short pause) NO no no BECAUSE I am /fúrìn (Note 2)/

In this extract, Clara initially asked Prof. Phil how to express her desire to order food that was not too spicy in Thai. Prof. Phil was the only person in the classroom who could answer the question since he spoke Thai. Clara had been in Thailand twice. She complained that her ordered food was often bland because many people over-generalized that she was sensitive to spicy food. They usually made food for her accordingly. In fact, medium spicy food was perfectly fine for her. Clara explained her situation in the first 3 lines. Prof. Phil proposed an adjectival phrase /maî ph' ${ }^{\mathrm{j} d}$ mâ:k/ ('not too spicy' in English) to her. In turn 5, Clara immediately expressed her disagreement without any softening devices. She insisted that she would want something spicy. Based on my observation, her disagreement was engendered by her limited knowledge of Thai. She probably did not understand the whole phrase unequivocally. However, her explicit disagreement was mitigated by an explanation. In turn 6, Prof. Phil described what she wanted and reiterated it to her. Clara explicitly disagreed with him again. She further explained that she would want spicy food that was similarly made for the professor. There was an overlap where the professor tried to repeat the same phrase to her. In turn 9, Clara expressed her third disagreement explicitly by reiterating the negative marker 'no' three times. Her explicit disagreement was softened by an explanation introduced by a discourse connective 'because' to explicate that she was a non-Thai person. Although the conversation went on, these turns are adequate to show how explicit disagreements were supported by the subsequent justification.

\section{Discussion and Conclusions}

American and Canadain cultures are often assumed to be comparable because they are similarly individualistic, independent and low-context (e.g., Hall, 1976; Hofstede, 1980; Markus \& Kitayama, 1991; Oyserman et al., 2002; Morling \& Lamoreaux, 2008). Moreover, their geographical habitations and religious traditions are compatible. Simply said, Americans and Canadians are native English speakers who have domiciles in North America. The religious tradition-Thanksgiving-is not celebrated in other English speaking countries, except in America and Canada. In these regards, Americans are obviously very similar to Canadians. However, these close similarities have been proved to be insufficient to govern their people's linguistic behaviors. In the same given context, the participants' expressions of disagreement did not necessarily conform to what has been widely tested 
to be the norm for Americans. Obviously, they normally used different disagreement strategies. Future researchers should thus be more careful when using a particular group of native English speakers. The preliminary results have proved that the two groups of native English speakers-Americans and Canadians-are different in terms of politeness strategies they used to disagree with the lecturer in the classroom context.

Last but not least, the excessive use of Americans as research participants is not literally weird as ones might literally interpret the WEIRD acronym according to Henrich et al. (2010). This current study by no means predisposes future researchers to eliminate American participants from their studies. However, they should be aware that disproportionate findings based on the narrowly defined samples could distort the ESL/EFL learners' perceptions of, or attitudes toward, all native English speakers. The learners might perhaps over-generalize from Americans' norm for student-lecturer disagreements to other native English speakers' norms. The availability of results based on other groups of native English speakers can inhibit these learners' over-generalizations. Provided an increasing number of studies with different groups of native English speakers as research participants, the learners will ponder about the variations across all native English speakers. The diversity of native English speakers used as research participants would definitely benefit the ESL/EFL learners.

\section{References}

Bardovi-Harlig, K. (2013). Developing L2 pragmatics. Language Learning, 63, Suppl.1, 68-86. http://dx.doi.org/10.1111/j.1467-9922.2012.00738.x

Beebe, L. M., \& Takahashi, T. (1989a). Do you have a bag? Social status and patterned variation in second language acquisition. In S. M. Gass, C. Madden, D. Preston, \& L. Selinker (Eds.), Variation in second language acquisition: Discourse and pragmatics (pp. 103-128). Clevedon: Multilingual Matters.

Beebe, L. M., \& Takahashi, T. (1989b). Sociolinguistic variation in face-threatening speech acts: Chastisement and disagreement. In M. Eisenstein (Ed.), The dynamic interlanguage (pp. 199-218). New York: Plenum. http://dx.doi.org/10.1007/978-1-4899-0900-8_13

Bjorge, A. K. (2012). Expressing disagreement in ELF business negotiations: theory and practice. Applied Linguistics, 33(4), 406-427. http://dx.doi.org/10.1093/applin/ams015

Brieger, N., \& Sweeney, S. (2000). The language of business English: grammar and functions. Essex: Pearson Education.

Brown, P., \& Stephen, L. (1987). Politeness: some universals in language usage. Cambridge: Cambridge University Press.

Charoenroop, P. (2014). A cross-cultural pragmatic study: politeness strategies and realizations of the strategies used to perform student-lecturer multiple disagreements by natives peakers of Thai and English. Journal of Educational and Social Research, 4(1), 146-157.

Chen, M. (2006). An Interlanguage study of the speech act of disagreement made by Chinese EFL speakers in Taiwan. Unpublished Doctoral Dissertation. National Sun Yat-Sen University.

Cohen, A. D. (1996). Developing the ability to perform speech acts. Studies in Second Language Acquisition, 18 (2), 253-267. http://dx.doi.org/10.1017/S027226310001490X

Dogancay-Aktuna, S., \& Kamisli, S. (1996). Linguistics of power and politeness in Turkish: revelations from speech acts. Paper presented at the Annual International Linguistics Conference (pp. 1-36). Turkey.

Emmerson, P. (2004). Email English. Oxford: Macmillan Publishers.

Gudykunst, W. B. (2001). Asian American ethnicity and communication. Thousand Oaks, California: Sage.

Gudykunst, W. B. (2003). Intercultural communication theories. In W. B. Gudykunst (Ed.), Cross-cultural and intercultural communication (pp. 167-189). Thousand Oaks: Sage.

Guodong, L., \& Jing, H. (2005). A contrastive study on disagreement strategies for politeness between American English and Mandarin Chinese. ASLAN EFL Journal, 7(1), 1-12.

Hall, E. T. (1976). Beyond Culture. New York: Anchor Press.

Henrich, J., Heine, S. J., \& Norenzayan, A. (2010). The weirdest people in the world? Behavioral and Brain Sciences, 33, 61-135. http://dx.doi.org/10.1017/S0140525X0999152X

Hofstede, G. (1980). Culture's consequences: International differences in work related values. Newbury Park, California: Sage.

Hofstede, G. (2001). Cultures and organizations: Software of the mind. London: McGraw-Hill. 
Jenkins, J. (2003). World Englishes: A resource book for students. London, Routledge.

Jone, L., \& Alexander, R. (2003). New International Business English Workbook. Cambridge: Cambridge University Press. http://dx.doi.org/10.1056/NEJMoa020286

Kachru, Y. (1992). Culture, style, and discourse: Expanding noetics of English. In B. Kachru (Ed.).

Kasper, G., \& Dahl, M. (1991). Research methods in interlanguage pragmatics. Studies in Second Language Acquisition, 13, 215-247. http://dx.doi.org/10.1017/S0272263100009955

Kieu, T. T. H. (2006). Disagreeing in English and Vietnamese: A pragmatic and conversational analysis perspective. Unpublished Doctoral Dissertation. Vietnam National University.

Locher, M. A. (2004). Power and politeness in action: Disagreements in oral communication. Berlin: Mouton de Gruyter. http://dx.doi.org/10.1515/9783110926552

Markus, H. R., \& Kitayama, S. (1991). Culture and the self: Implications for cognition, emotion and motivation. Psychological Review, 98, 224-253. http://dx.doi.org/10.1037/0033-295X.98.2.224

Morling, B., \& Lamoreaux, M. (2008). Measuring culture outside the head: A metaanalysis of individualism-collectivism in cultural products. Personality and Social Psychology Review, 12, 199-221. http://dx.doi.org/10.1177/1088868308318260

Oyserman, D., et al. (2002). Rethinking individualism and collectivism: Evaluation of theoretical assumptions and meta-analyses. Psychological Bulletin, 128, 1173-1175. http://dx.doi.org/10.1037/0033-2909.128.1.3

Rees-Miller, J. (2000). Power, severity and context in disagreement. Journal of Pragmatics, 32, 1087-1111. http://dx.doi.org/10.1016/S0378-2166(99)00088-0

Scollon, R., \& Scollon, S. (1995). Intercultural Communication. Oxford: Blackwell.

Sweeney, S. (2003). English for business communication. Cambridge: Cambridge University Press.

Takahashi, T., \& Beebe, L. M. (1993). Cross-linguistic influence in the speech act of correction. In G. Kasper, \& S. Blum-Kulka (Eds.), Interlanguage Pragmatics (pp. 138-157). New York: Oxford University Press.

Varner, I., \& Beamer, L. (2005). Intercultural communication in the global workplace. McGraw-Hill: New York.

Walkinshaw, I. (2007). Power and disagreement: Insights into Japanese learners of English. RELC Journal, 38, 278-300. http://dx.doi.org/10.1177/0033688207085848

Yuan, Y. (2001). An inquiry into empirical pragmatics data-gathering methods: written DCTs, oral DCTs, field notes, and natural conversations. Journal of Pragmatics, 33, 271-292. http://dx.doi.org/10.1016/S0378-2166(00)00031-X

\section{Notes}

Note 1. British English, Canadians, Australians, New Zealanders and South-Africans are officially native speakers of English (cf. Kachru, 1992, p. 356 and Jenkins, 2003, p. 14).

Note 2. A generic Thai word used to address white Westerners regardless of their nationality and race.

\section{Appendix A}

The conventions of paralinguistic features used in the study, adapted from Locher (2004)

$1 \quad$ : A backslash is used to indicate a falling intonation.

/ : A slash is used to indicate a rising intonation.

CAPS : Capital letters carry the primary stress in a monosyllable word.

$=\quad:$ In order to show an immediate connection between two turns uttered by the lecturer and the student.

$::: \quad$ : Colons are used to indicate lengthened vowels

[...] : Square brackets indicate speech overlap uttered by lecturer and student or vice versa.

(a) : This symbol is used to represent laughter in syllable.

$\mathrm{X} \quad$ : The letter $\mathrm{X}$ indicates an unclear or unintelligible syllable or word.

A...A : Utterances marked by this are rapid speech. 
S...S : Utterances marked by this are slow speech.

P...P : Utterances marked by this are soft.

(a...@ : Utterances marked by this are produced with laughs.

\section{Appendix B}

Disagreement Strategies Used by the Participants

\begin{tabular}{lll}
\hline Disagreement Strategies (cf. Table 2) & Frequency & Percentage \\
\hline Explicit + Justification & 67 & 62.03 \\
Unmitigated + Justification & 21 & 19.45 \\
Delayed + Internally Mitigated & 2 & 1.85 \\
Delayed + Justification & 3 & 2.78 \\
Internally Mitigated + Justification & 11 & 10.18 \\
Delayed + Internally Mitigated + Justification & 4 & 3.71 \\
Total & 108 & 100 \\
\hline
\end{tabular}

\section{Examples of Disagreement Strategies}

Explicit + Justification

$\mathrm{S} \longrightarrow$ L: No, this isn't acceptable!

Unmitigated + Justification

$\mathrm{S} \longrightarrow \mathrm{L}$ : This is not practical (short pause) nobody uses it!

Delayed + Internally Mitigated

$\mathrm{S} \longrightarrow \mathrm{L}:$ Well! it might not be too expensive.

Delayed + Justification

$\mathrm{S} \longrightarrow$ L: I think it's weird because I've not seen it before!

Internally Mitigated + Justification

$\mathrm{S} \longrightarrow$ L: They shouldn't register for the course because it's too expensive for them!

Delayed + Internally Mitigated + Justification

$\mathrm{S} \longrightarrow$ L: Oh, it couldn't be too complicated because we've learned it before.

\section{Copyrights}

Copyright for this article is retained by the author(s), with first publication rights granted to the journal.

This is an open-access article distributed under the terms and conditions of the Creative Commons Attribution license (http://creativecommons.org/licenses/by/3.0/). 